\title{
AN UNUSUAL ASCALAPHID LARVA (NEUROPTERA: ASCALAPHIDAE) FROM SOUTHERN AFRICA, WITH COMMENTS ON LARVAL EVOLUTION WITHIN THE MYRMELEONTOIDEA*
}

\author{
By Charles S. Henry \\ Biological Sciences Group, University of Connecticut, Storrs 06268
}

Ascalaphidae is a fairly large family of planipennian Neuroptera that has received little attention from taxonomists since Weele's 1908 monograph. Life history and behavioral studies of the group have suffered even greater neglect; what is known has been summarized in a previous work (Henry, 1977). As an order, Neuroptera is taxonomically intractable, largely due to difficulty in interpreting wing venation: extreme convergence is common in distantly related families, yet divergence often occurs within a single subfamily or genus. For this reason, the immature stages have proven to be more reliable indicators of relationship than the adults, and our present understanding of evolution within the order is based more on larval than adult features (Withycombe, 1925; MacLeod, 1970). Since such considerations apply as strongly to Ascalaphidae as they do to other Neuroptera, all larval or life-history data are of paramount importance to phylogenetic studies of the family.

Described here is a peculiar ascalaphid larva from Mkuze Game Park, Natal, collected in November of 1967 by J. A. Slater and T. Schuh. Although it shows all the diagnostic features of the family, certain details of its setal morphology and of the form and distribution of its thoracic and abdominal extensions (scoli) are unique and of great phylogenetic importance. As the larva is (necessarily) unassociated with an adult, I will describe its major features informally and compare them critically with those of larvae of known taxa in an attempt to deduce the general systematic position of the insect. In addition, I will summarize what is known of larval morphology in the superfamily Myrmeleontoidea, so that conclusions concerning the Mkuse specimen can be placed in perspective.

\footnotetext{
*Manuscript received by the editor December 12, 1978.
} 


\section{METHODS AND MATERIALS}

The larva was preserved in 70 percent ethanol. Wild ${ }^{\mathrm{TM}} \mathrm{M} 5$ and M5A stereoscopic dissecting microscopes were used to observe the specimen, while drawings were made by means of integral camera lucida attachments for these instruments.

\section{DESCRIPTION OF LARVA}

The African specimen is a typical ascalaphid immature in most respects (Fig. 1), displaying robust jaws with three mandibular teeth, large squarish head with pronounced occipital angles, prominent ocular tubercles each bearing six dorsal and one ventral stemmata, and compact, lightly sclerotized body fringed by numerous finger-like, setigerous extensions. It measures about $7 \mathrm{~mm}$ from labral margin to anal spinneret and is probably a partially grown second instar. Previous studies of ascalaphid immatures (Henry, 1976) indicate that important features of the mature larva that may be absent or distorted in the first instar are expressed quite clearly by the second stadium; for this reason, the following description can be compared with existing descriptions of third instar larvae.

The head capsule is of the generalized ascalaphid type in shape, more square than cordate, without extreme dorso-ventral flattening. Ocular tubercles (Fig. 2-A) are cylindroid, and the ventral stemma on each is but slightly reduced compared with the dorsal ones. The antennal tubercles are poorly developed. Jaws are straight-shanked, each tapering smoothly from proximal tooth to tip; the distal tooth is markedly smaller than the others. Ventrally, sclerites of the mouthpart bases and the pieces of the labium (Fig. 2-B) have a generalized form and relationship to one another (Henry, 1976). The manner of ventral articulation of the mandibles to the head capsule is also relatively unspecialized: each condyle bears against a median lobe at the end of the subgenal ridge rather than being retained more positively by a U-shaped socket.

The body of the specimen also exhibits several apparently primitive traits. Twelve pairs of long primary scoli fringe the body from mesothorax to eighth abdominal segment (Fig. 1); in addition, a pair of equally prominent ventro-lateral secondary scoli occurs on abdominal segments I-VII (Fig. 3). All scoli are slightly flattened dorso-ventrally and possess a border of specialized setae (see below). The eight pairs of abdominal spiracles are situated laterally 


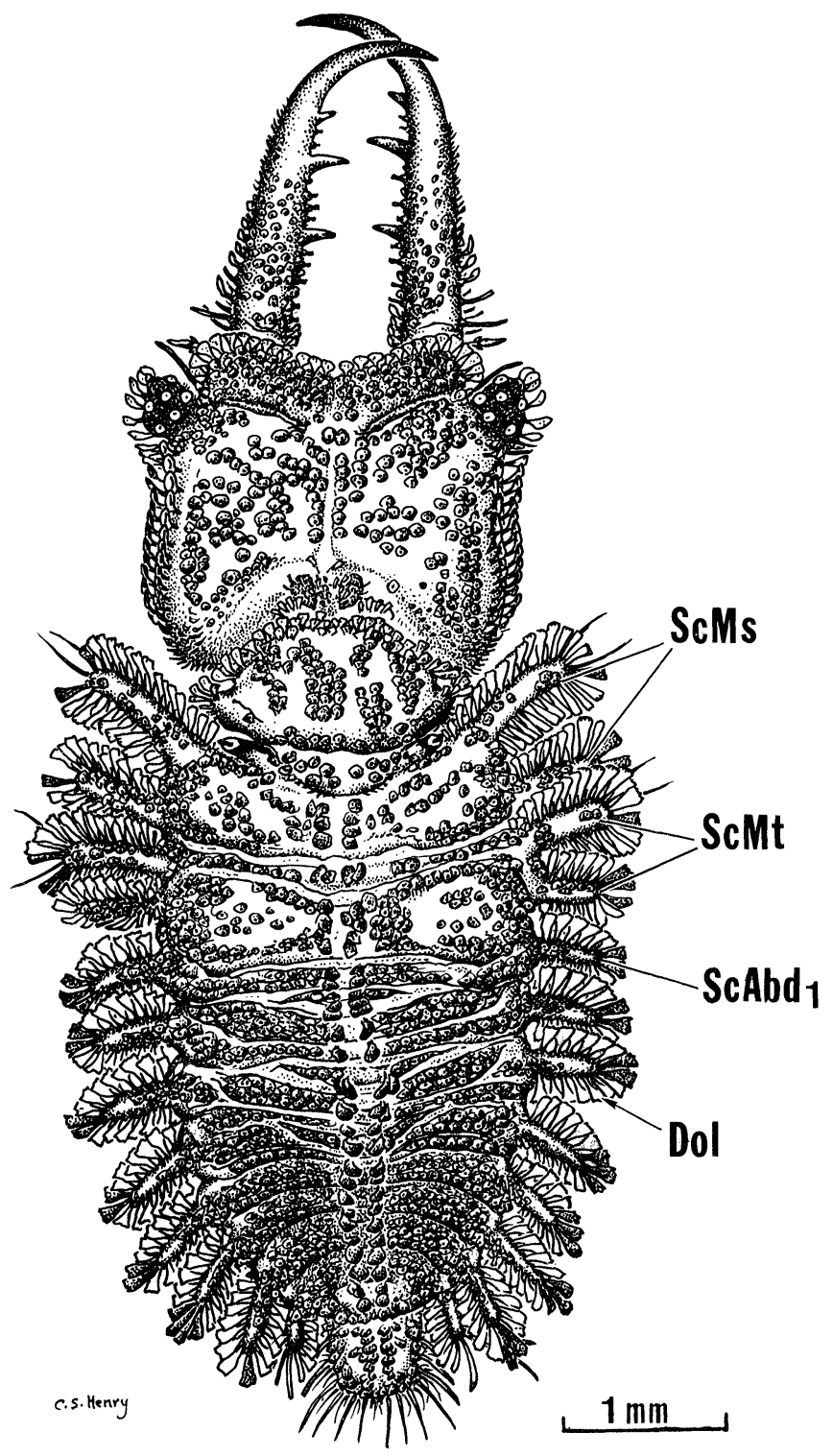

Figure 1. Mkuze ascalaphid larva, probably second instar. $\mathrm{ScMs}=$ mesothoracic scoli, $\mathrm{ScMt}=$ metathoracic scoli, $\mathrm{ScAbd} \mathrm{A}_{1}=$ scoli of first abdominal segment, $\mathrm{Dol}=$ dolichasterine seta. 
in a linear arrangement between the primary and secondary series of scoli; the eighth abdominal segment, lacking ventral scoli, bears its spiracles beneath the primary scoli.

Nearly all setae are highly modified (Figs. 1-3). Those clothing most of the dorsal and ventral surfaces of the head, body, and scoli are very short and flattened into round discs or scales. Large, dorsoventrally flattened dolichasters project from the labral margin and fringe the ocular tubercle and each primary and secondary scolus. Spoon-shaped dolichasters occur dorsally in a double row down the mid-line of the body and in a triple series on each side of the head capsule. Long setae of conventional shape are present in small numbers on the tips of the first and third scoli of the thorax and singly on the tip of each scolus of the ventral abdominal series; the last primary scolus also bears a few terminal setae of this type.

The pigmentation pattern of the specimen is due primarily to the scale-like setae that cover nearly all parts of the body. In general the insect has a mottled appearance, as though adapted for crypsis in a relatively exposed or open microhabitat; however, its true colors are of course unknown. The ocular tubercles are conspicuously darker and the tips of the scoli lighter than other parts of the larva; otherwise, mottling is quite uniform.

\section{DISCUSSION}

The Ascalaphidae is one of six families in the superfamily Myrmeleontoidea, a complex defined by a common larval type exhibiting an array of cephalic traits that apparently evolved together to provide structural support for the large muscles and condyles of the jaw "trap" mechanism (MacLeod, 1964, 1970). In contrast to the hemerobiiform larva of other Planipennia, that of Myrmeleontoidea (=Infraorder Myrmeleontiformia) displays 1) maxillary blade lance-like, never as broad as mandible; 2) robust, sickle-shaped mandibles; 3) ventral surface of large quadrate head convex and heavily sclerotized, with sclerites of maxillae and labium confined to medial anterior region; 4) pronounced anteriad migration and torsion of the tentorium so that it assumes a dorso-ventral orientation connecting the anterior tentorial pits above to the osterior ones directly below; 5) relatively short antenna with thick cape but filiform distal portion; and 6) two- to four-segmented labial palps each arising from the tip of a large, palpimere-like structure that actually represents half of the divided prelabium. 

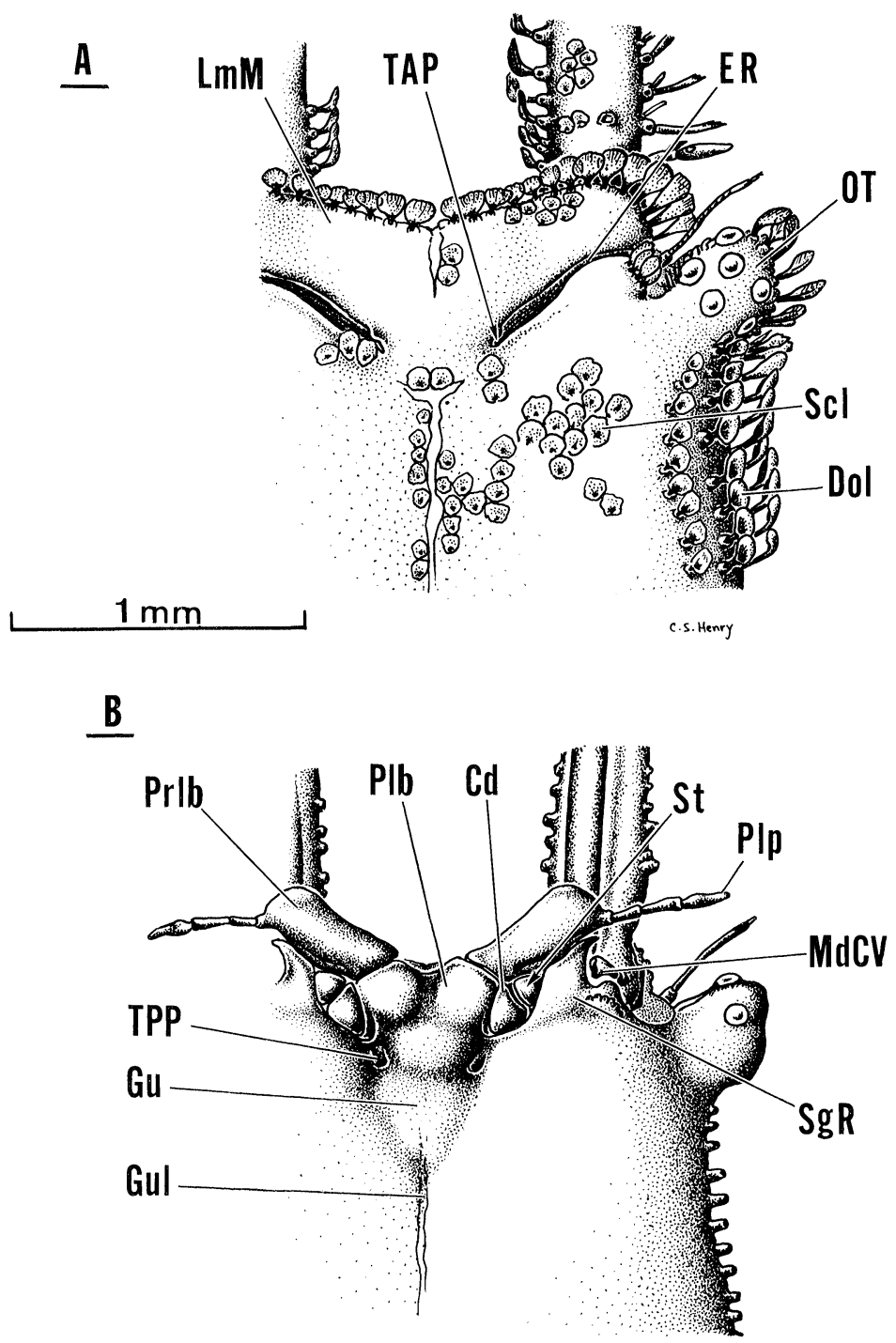

Figure 2. Mkuze larva, details of head capsule. $\mathrm{A}=$ anterior dorsal aspect, $\mathrm{B}=$ anterior ventral aspect. $\mathrm{Cd}=$ maxillary cardo, $\mathrm{Dol}=$ dolichaster, $\mathrm{ER}=$ epistomal ridge, $\mathrm{Gu}=$ gular area, $\mathrm{Gul}=$ gular line, $\mathrm{LmM}=$ labral margin, $\mathrm{MdCV}=$ ventral mandibular condyle, $\mathrm{OT}=$ ocular tubercle, $\mathrm{Plb}=$ postlabium, $\mathrm{Prlb}=$ prelabial lobe, $\mathrm{Plp}=$ labial palp, $\mathrm{Scl}=$ scale-like seta, $\mathrm{SgR}=$ subgenal ridge, $\mathrm{St}=$ maxillary stipes, $\mathrm{TAP}=$ anterior tentorial pit, TPP $=$ posterior tentorial pit. 
Psychopsidae appears to be the most generalized of myrmeleontoid families with respect to these larval features (Fig. 4). Basic specializations that have originated within the assemblage include the development of mandibular teeth (all families except Psychopsidae), elaboration of setigerous tubercles or scoli on the sides of the body (all except Psychopsidae and Nemopteridae), increase in the number of pairs of stemmata to seven (all except Psychopsidae and most Nymphidae), appearance of distinct ocular tubercles (Ascalaphidae, Stilbopterygidae, and Myrmeleontidae), fusion of tarsus with tibia in the metathoracic leg (same three families), and great enlargement of hind tarsal claws (Stilbopterygidae and Myrmeleontidae). Available evidence suggests a sister-group relationship between Nymphidae and all other families except Psychopsidae (MacLeod, 1970); Ascalaphidae in turn is probably the sister-group to Myrmeleontidae (Riek, 1976), while the stilbopterygids-at least, those from Australia-may prove to be nothing more than specialized ant-lions (manuscript in preparation).

As discussed in an earlier paper (Henry, 1976), several larval specializations appear within the Ascalaphidae (Fig. 4). For example, New World ascalaphine (split-eyed) forms of the genus Ululodes Currie and Colobopterus Rambur manifest extensively modified cordate heads and a complex of mouthpart specializations, all relating to an extreme $270^{\circ}$ "trap" position of the jaws; these larvae also possess fewer and longer body scoli (ten pairs) than other taxa, show no trace of a ventral scolus series, and bear al

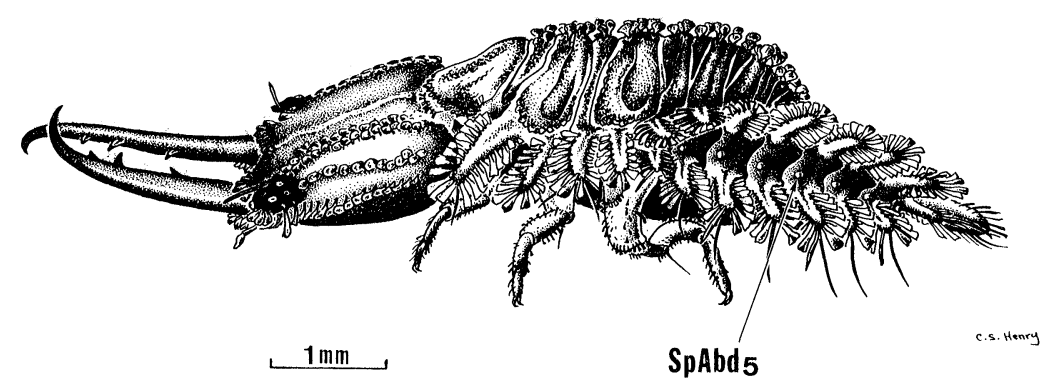

Figure 3. Mkuze larva, lateral view. $\mathrm{SpAbd}_{5}=$ spiracle of fifth abdominal segment. 


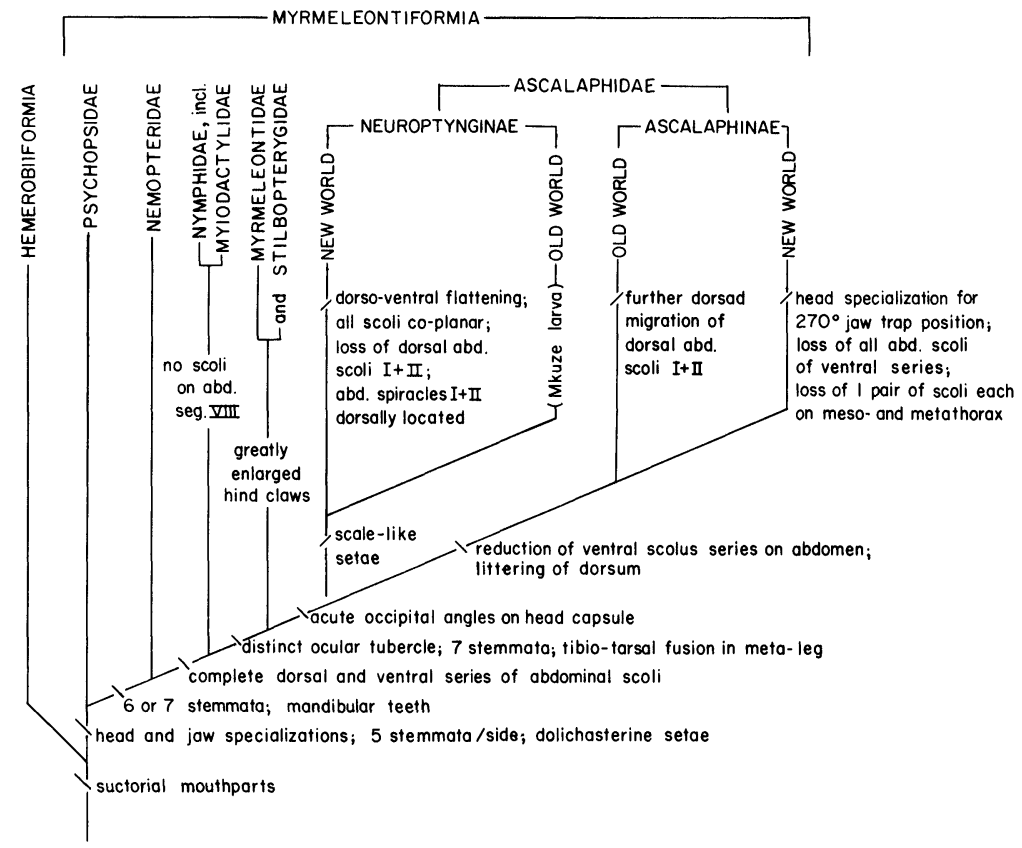

Figure 4. Cladogram of myrmeleontoid families of planipennian Neuroptera, based upon larval features.

abdominal spiracles ventrally. In contrast, New World neuroptyngine (entire-eyed) forms like Ascaloptnyx Banks and Byas Rambur (Henry, 1978) show extreme dorso-ventral flattening and a much larger number of scoli-twelve primary and six secondary (smaller) pairs, the latter placed just anteriad of the former on abdominal segments III-VIII. In addition, abdominal spiracles I and II are dorsally located in these neuroptyngines, and specialized scale-like dolichasters predominate on their body surfaces. Known Old World ascalaphines, on the other hand, resemble Nymphidae in possessing both a dorsal and ventral series of scoli on the abdomen and laterally located abdominal spiracles; however, at least in Ascalaphus Fabricius, ${ }^{1}$ the ventral series is largely vestigial and the first

'Tjeder (1972) points out that Ascalaphus as used here and as previously understood should be replaced for nomenclatural reasons by Libelloides Schäffer; Ascalaphus Fabricius then replaces Helicomitus McLachlan. 
two pairs of abdominal spiracles show signs of dorsal migration (Henry, 1976, Fig. 10). Finally, the Oligocene Neadelphus protae MacLeod displays ventral spiracle location and is devoid of ventral scoli, vestigial or otherwise, but those it possesses number twelve rather than the ten of Ululodes and its relatives; it also shows no setal modification (MacLeod, 1970; Henry, 1976, Fig. 9).

MacLeod (1970) interprets the secondary abdominal scoli of New World neuroptyngines as having migrated from the ventral series of a non-flattened nymphid-like ascalaphid ancestor. My own view, based on analysis of changes in spiracle location and comparison of scolus shapes, is that the primary rather than secondary scoli of these neuroptyngines have been derived from the ventral series, and that the primary abdominal scoli of Neuroptynginae and Ascalaphinae are therefore not homologous (Henry, 1976).

The Mkuze specimen described here shares its general head capsule morphology and its twelve pairs of primary body scoli with Neadelphus and known extant Neuroptynginae and Old World Ascalaphinae; in both respects, it is a primitive or generalized ascalaphid. Its most remarkable feature, however, is the double row of scoli on each side of its abdomen with spiracles placed laterally between the rows: although Ascalaphus shows traces of the ventral series and New World neuroptyngines bear the latter in the same plane as the dorsal series, no larva possesses such a fully developed double series nor so closely approaches MacLeod's hypothetical nymphid-like ancestor as this specimen.

The setal patterns on the scoli of the specimen may help to homologize these protuberances in this and other ascalaphid larvae. For example, it is not known which (if either) of the two pairs of scoli on the mesothorax or on the metathorax represent the dorsal series, since spiracles are not present on either segment and all known taxa showing the condition bear both pairs in the same plane. The Mkuze larva possesses sharp-tipped setae on the tips of the first and third pairs of thoracic scoli and on all ventral scoli, suggesting a ventral origin for the more anteriorly placed pair of scoli on each thoracic segment. Actually, the same relationship is also present in Ascaloptynx: the first and third thoracic scoli resemble in shape those deduced to belong to the ventral abdominal series (Henry, 1976, Fig. 5). It then follows that, in neuroptyngine larvae bearing all acoli in a common plane, the anterior scoli on each thoracic segment did not originate from the same series as did 
the anterior ones on each abdominal segment. This conclusion should be tested further.

Although the African specimen is primitive or generalized in most respects, its scale-like setae and flattened dolichasters are a significant specialization shared only with New World Neuroptynginae. Based upon this single apomorphy, the larva could be classified with the Neuroptynginae, for which no larvae are known from the Old World; the dorsal location of abdominal spiracles I and II of New World forms could then be interpreted as an additional specialization within a subgroup of the subfamily, associated with scolus migration in response to dorso-ventral flattening and exposed living habits.

\section{ACKNOWLEDGEMENTS}

This work was made possible by grants to the author from the Research Foundation of The University of Connecticut (Storrs) and from the National Science Foundation (DEB77-12443). I thank Dr. James A. Slater (University of Connecticut) for loan of the Mkuze specimen from his personal collection and for his constructive comments on the manuscript. Ms. Marian Gergler kindly typed and edited the manuscript, while Ms. Mary Jane Spring prepared the cladogram reproduced in Fig. 4.

\section{REFERENCES}

HENRY, C. S.

1976. Some aspects of the external morphology of larval owlflies (Neuroptera: Ascalaphidae), with particular reference to Ululodes and Ascaloptynx. Psyche 83(1): 1-31.

1977. The behavior and life histories of two North American ascalaphids. Ann. Entomol. Soc. Am. 70(2): 179-195.

1978. The egg, repagulum, and larva of Byas albistigma (Neuroptera: Ascalaphidae): morphology, behaviour and phylogenetic significance. Syst. Entomol. 3: 9-18.

MACLEOD, E. G.

1964. A comparative morphological study of the head capsule and cervix of larval Neuroptera (Insecta). Ph.D. thesis, Harvard University, Cambridge, Mass.

1970. The Neuroptera of the Baltic Amber. I. Ascalaphidae, Nymphidae, and Psychopsidae. Psyche 77: 147-180.

RIEK, E. F.

1976. The family Stilbopterygidae (Neuroptera) in Australia. J. Aust. Entomol. Soc. 15: 297-302. 
TJEDER, B.

1972. Two necessary alterations in long-established genus nomenclature in Ascalaphidae (Neuroptera). Entomol. Scand. 3: 153-155.

WeEle, H. W. van DER.

1908. Ascalaphiden: Monographisch Bearbeitet. Coll. Zool. Selys-Longchamps fasc. 8: $1-326$.

WithyсомBE, C. L.

1925. Some aspects of the biology and morphology of the Neuroptera. With special reference to the immature stages and their possible phylogenetic significance. Trans. R. Entomol. Soc. London. 72: 303-411. 

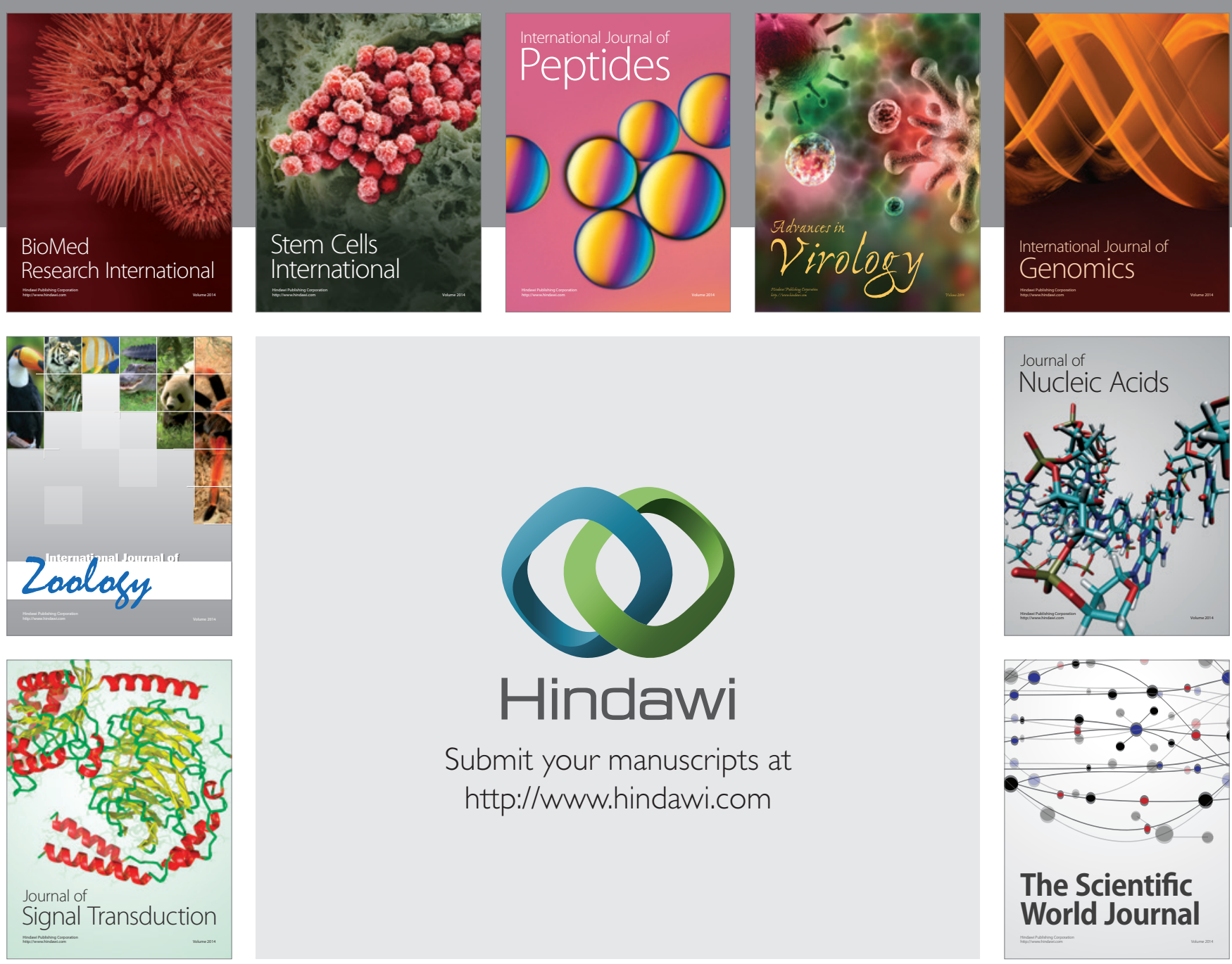

Submit your manuscripts at

http://www.hindawi.com
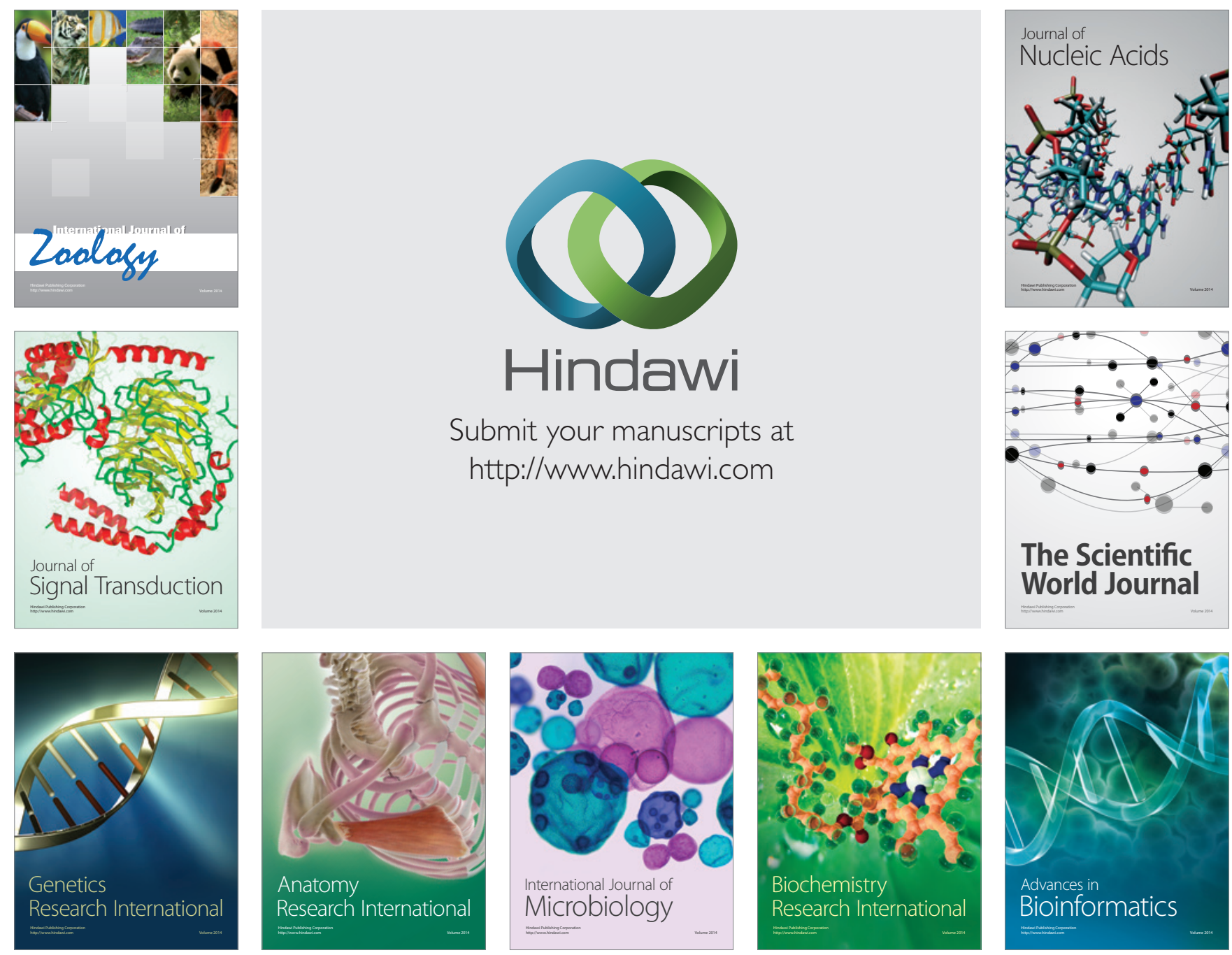

The Scientific World Journal
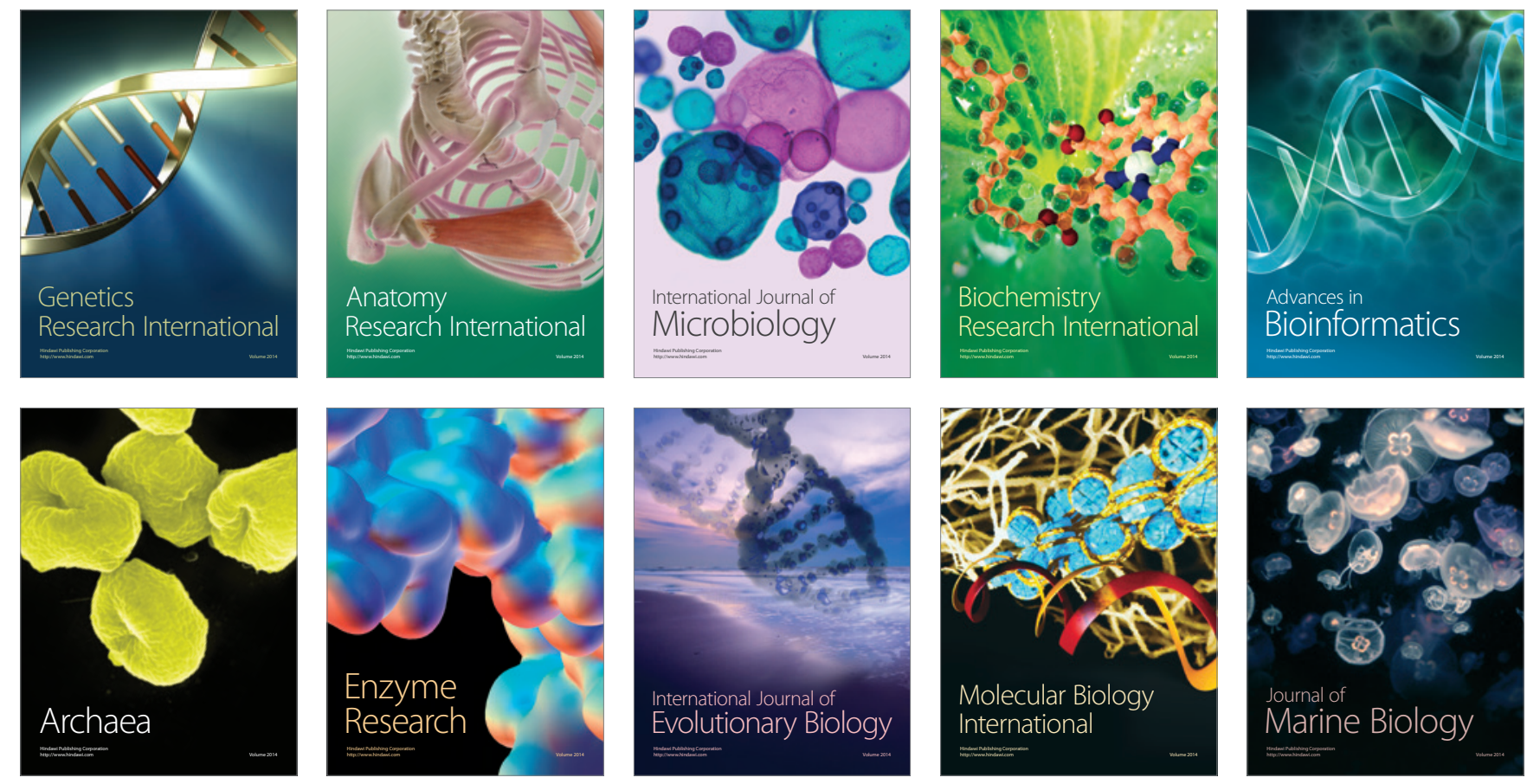